Article

\title{
Invasive Fungal Infections in Under-Five Diarrheal Children: Experience from an Urban Diarrheal Disease Hospital
}

\author{
Nusrat Jahan Shaly ${ }^{1}$, Mohammed Moshtaq Pervez ${ }^{1}$, Sayeeda Huq ${ }^{1}$, Dilruba Ahmed ${ }^{1}$, \\ Chowdhury Rafiqul Ahsan ${ }^{2}$, Monira Sarmin ${ }^{1}$, Farzana Afroze ${ }^{1}{ }^{1}$, Sharika Nuzhat ${ }^{1}$, \\ Mohammod Jobayer Chisti ${ }^{1, *}$ and Tahmeed Ahmed ${ }^{1}$
}

check for

updates

Citation: Shaly, N.J.; Pervez, M.M.; Huq, S.; Ahmed, D.; Ahsan, C.R.; Sarmin, M.; Afroze, F.; Nuzhat, S.; Chisti, M.J.; Ahmed, T. Invasive Fungal Infections in Under-Five Diarrheal Children: Experience from an Urban Diarrheal Disease Hospital. Life 2022, 12, 94 . https:/ / doi.org/ $10.3390 /$ life12010094

Academic Editor: Eleonora Gaetani

Received: 9 December 2021

Accepted: 5 January 2022

Published: 10 January 2022

Publisher's Note: MDPI stays neutral with regard to jurisdictional claims in published maps and institutional affiliations.

Copyright: (C) 2022 by the authors. Licensee MDPI, Basel, Switzerland. This article is an open access article distributed under the terms and conditions of the Creative Commons Attribution (CC BY) license (https:// creativecommons.org/licenses/by/ $4.0 /)$.
1 International Centre for Diarrhoeal Disease Research, Bangladesh (icddr,b), Mohakhali, Dhaka 1212, Bangladesh; nusrat.jahan@icddrb.org (N.J.S.); pervez@icddrb.org (M.M.P.); sayeeda@icddrb.org (S.H.); dahmed@icddrb.org (D.A.); drmonira@icddrb.org (M.S.); farzanaafroz@icddrb.org (F.A.); sharika.nuzhat@icddrb.org (S.N.); tahmeed@icddrb.org (T.A.)

2 Department of Microbiology, University of Dhaka, Dhaka 1000, Bangladesh; crahsan@du.ac.bd

* Correspondence: chisti@icddrb.org

\begin{abstract}
Invasive fungal infections (IFIs) are opportunistic, especially in immunocompromised and hospitalized patients. Children with IFIs are more vulnerable to a fatal outcome. For early diagnosis and treatment, knowledge of the spectrum and frequency of IFIs among children is prerequisite. In this prospective observational study, we enrolled 168 children of 2-59 months old of either sex from March 2018 to December 2019 admitted to the Dhaka hospital, icddr,b. Study participants with suspected IFIs were with or without severe acute malnutrition (SAM) along with sepsis/pneumonia and fulfilled any of the following criteria: (i) failure to respond to injectable antibiotics, (ii) development of a late-onset hospital-acquired infection, (iii) needed ICU care for $>7$ days, (iv) took steroids/antibiotics for $>2$ weeks before hospitalization, and (v) developed thrush after taking injectable antibiotics. The comparison group included non-SAM (weight-for-length $\mathrm{Z}$ score $\geq-2$ ) children with diarrhea and fever $<3$ days in the absence of co-morbidity. We performed real-time PCR, ELISA, and blood culture for the detection of fungal pathogen. Study group children with SAM, positive ELISA and PCR considered to have a IFIs. In the study group, 15/138 (10.87\%) children had IFIs. Among IFIs, invasive candidiasis, aspergillosis, histoplasmosis detected in 6 (4.53\%), 11 $(7.97 \%)$, and $1(0.72 \%)$ children, respectively, and $(3 / 15[2.17 \%])$ children had both candidiasis and aspergillosis. Children with IFIs more often encountered septic shock $(26.7 \%$ vs. $4.9 \% ; p=0.013)$ and had a higher death rate $(46.7 \%$ vs. $8.9 \% ; p<0.001)$ than those without IFIs. IFIs were independently associated with female sex $(\mathrm{OR}=3.48 ; 95 \% \mathrm{CI}=1.05,11.55 ; p=0.042)$ after adjusting for potential confounders. Our findings thus implicate that, malnourished children with septic shock require targeted screening for the early diagnosis and prompt management of IFIs that may help to reduce IFIs related deaths.
\end{abstract}

Keywords: invasive fungal infections; malnutrition; under-5-year-old children; diarrhea; death

\section{Introduction}

Invasive fungal infections (IFIs) are foremost causes of morbidity and mortality among the critically ill and immunosuppressed pediatric patients in intensive care units (ICU) [1] IFIs are most commonly caused by Candida spp., Aspergillus spp., Cryptococcus spp., Histoplasma capsulatum, Coccidioide simmitis, Paracoccidioides spp., and Fusarium spp. [2]. A study among children with acute lymphoblastic leukemia (ALL) found that the prevalence of IFI was $9.7 \%$ [3]. IFIs result from the defects in immune mechanisms among the immunosuppressed individuals and invasive procedures [1]. The pathogen enters through the puncture sites of the skin, gastrointestinal tract lesion, indwelling catheters and is spread by the hematogenous route in different parts of the body [4]. Immunodeficient children 
with malignancy, malnutrition, and prematurity were reported to be susceptible to develop IFIs [5]. Prolonged use of antibiotics, corticosteroids, chemotherapy, invasive procedure, and longer duration of hospital stay were identified as the critical risk factors for IFIs [6]. It was documented that IFIs were associated with higher mortality among children ranging from $23 \%$ to $48.2 \%[7,8]$.

Candidemia is the leading IFI; with an incidence rate between 4.3 to 8.1 cases $/ 10,000$ admissions $[9,10]$. Among IFIs, Candida species were found to be responsible for $59.1 \%$ of infections among pediatric acute myeloid leukemia patients in Taiwan [11]. In the gastrointestinal tract, commensal candida translocate, spread hematogenously, and colonize, resulting in deep-seated candidiasis [12]. Globally the incidence of nosocomial candidiasis has increased in infants and children in tertiary care centers. A Turkish study found that the incidence of nosocomial candidemia ranged from 3.2 to 6.9 per 1000 admissions over nine years [13]. In ICU settings, it was responsible for $10 \%$ to $42 \%$ of all bloodstream infections (BSIs) and the fourth most common BSI pathogen in children $[14,15]$.

Among molds, Aspergillus spp. was the primary cause of IFI. The rate of invasive aspergillosis was around $0.4 \%$ among the hospitalized immunocompromised children in the United States [16]. In children with invasive aspergillosis, lungs and sinuses are the main sites of infection. About $85 \%$ of lung infections were found in children with probable IFD caused by Aspergillus [7]. However, many children may not present with the manifestation of respiratory disease. Sometimes cough, hypoxemia, and tachypnea are present in children with invasive aspergillosis [17]. In pediatric patients, the mortality rate was $15.8 \%$ and $18 \%$ with invasive candidiasis (IC) and invasive aspergillosis (IA), respectively. Both IC and IA have been reported to increase the duration of hospital stay $[9,16]$.

Histoplasmosis is usually a self-limiting condition in children with a normal immune system. Besides the living environment, malnutrition was identified as the most important risk factor for severe and disseminated histoplasmosis due to a poor immune system. Children may present with fever, cough, headache, and lymphadenopathy. Pulmonary infiltrate was the most common finding (83\%) [18].

A study done by Gurgani and his colleagues revealed the burden of several serious fungal infections in Bangladesh (28). Superficial mycoses and dermatomycoses are common in rural areas and tertiary level hospital outpatient departments $[19,20]$. Systemic mycoses are also documented as a significant emerging problem [21-26]. In developing countries like Bangladesh, the high malnutrition rates [27] with accompanying immunosuppression may result in a higher burden of IFIs. Additionally, immunosuppressed kids are at risk of developing dispersed candidiasis [28]. However, life-threatening invasive fungal infections are presumed to be increasing in Bangladesh. Data on the prevalence of invasive fungal infections among critically ill or ICU admitted children are limited in Bangladesh [29]. Moreover, diagnosis of IFI is difficult. However, fungal culture and microscopy are considered the gold standard with some limitations. The newer tests Platellia ${ }^{\mathrm{TM}}$ Aspergillus for galactomannan antigen, Fungitell kit for beta-D-Glucan detection, or PCR assay are either unavailable or not performed routinely in most healthcare settings in Bangladesh [30]. Hence, we observed increasing use of systemic anti-fungal for critically ill or ICU patients who were non-responsive to front-line antibiotics. Thus, patients may suffer from drug related side effects or risk of emergence of drug-resistant fungal strains [31,32].

A study conducted in the Dhaka hospital of icddr,b among under-5-year-old children with diarrhea and bacteremia from Dhaka hospital found that only $17 \%$ had bacterial isolates from blood, and 10\% were pathogenic bacteria. Comparing death and survivor, bacterial isolates in stool were $25 \%$ and $26 \%$, respectively [33]. It was perceived that IFIs may be prevalent in these children. However, there is inadequate information regarding the proportion, presenting features, and outcome of these hospitalized children having invasive fungal infections. To develop an optimal management protocol, we require extensive understanding of the epidemiology of IFIs. Thus, our study was focused on determining the spectrum and frequency of invasive fungal infections caused by Candida species, 
Pneumocystis jirovecii, Aspergillus species, Cryptococcus species, Histoplasma Capsulatum, and their associated factors, outcome among under-5-year-old diarrheal children.

\section{Materials and Methods}

\subsection{Ethics Statement}

This study was approved (protocol number-PR-17069) by the institutional review boards (IRB) of the International Centre for Diarrheal Disease Research, Bangladesh (icddr,b), comprised of the Research Review Committee (RRC) and the Ethical Review Committee (ERC). Signed informed consents were obtained from the parents/legal guardians of the participating children before enrollment. The consent form was written and formatted in Bengali for a proper understanding of the caregivers.

\subsection{Study Setting}

The study was conducted at the Dhaka Hospital of icddr,b between March 2018 and December 2019. Critically ill patients were treated in the Intensive Care Unit (ICU) of Dhaka Hospital, equipped with necessary life support measures, including non-invasive and invasive ventilator supports. According to the 2019-2020 annual report, Dhaka hospital, the largest diarrheal treatment center in the world, treated around 200,000 patients. More than half of these patients (57.2\%) were under five years of age. Among under-5-year-old children, those with severe acute malnutrition (SAM) with or without severe pneumonia and/or sepsis conventionally receive broad-spectrum antibiotics. icddr,b possesses a wellequipped diagnostic laboratory facility capable of performing all the clinical tests, including real-time PCR (Polymerase Chain Reaction), ELISA (Enzyme-Linked Immunosorbent Assay) required to detect fungal etiology.

\subsection{Study Design}

It was a prospectively conducted observational study.

\subsection{Study Group}

The study children with suspected invasive fungal infections were 2-59-month-old children of either sex with or without severe acute malnutrition (SAM) along with sepsis/pneumonia and fulfilled any of the following criteria: (i) Failed to respond injectable antibiotics (first line-Ampicillin plus gentamicin, second line-Ceftriaxone plus levofloxacin); (ii) children with SAM or had a history of recent measles or any condition that induced immune suppression plus failure to respond to first line antibiotics (first line antibiotics-Ampicillin + Gentamicin); (iii) developed a late-onset hospital-acquired infection; (iv) needed ICU care for more than seven days; (v) took steroids or antibiotics for more than two weeks before hospitalization; or (vi) developed thrush after taking second line antibiotics.

\subsection{Comparison Group}

Children from the short-stay unit (SSU) or outpatient department (OPD) of Dhaka hospital were eligible for the comparison group. They had either diarrhea or fever (less than 3 days) but non-SAM (Weight-for-length $Z$ score $\geq-2$ ). We excluded the children with cough, persistent diarrhea, congenital anomaly, or medical/surgical co-morbidity or who received antibiotics for the current illness before hospitalization.

\subsection{Sample Size}

\subsubsection{Study Group}

A study from the India found that the prevalence of nosocomial candidemia infection among the general population was $6.5 \%[34,35]$ and another US based study among HIVinfected children from the out-patient department was 6\% [36]. We anticipated a higher prevalence of IFIs among our study children who failed to respond to antibiotics for 
pneumonia or sepsis. With $80 \%$ power and $5 \%$ type I error and considering $10 \%$ prevalence of IFIs among 2-59 months old children in our in-patient ward, we required 138 children.

\subsubsection{Comparison Group}

We observed most of our study children were positive for at least one fungal pathogen with or without the potential fungal disease. A proportion of them treated with the antifungal drug depending on the adjudication of ICU consultants. To mitigate the question of whether these fungi were responsible for the IFIs among the study children or not, we selected a comparison group from healthy children. Therefore, we enrolled 30 healthy children purposively after completion of enrollment of study children by an amendment of the protocol approved by our IRB.

\subsection{Patient Management}

According to the hospital's standard management guidelines, the enrolled children received management either in the ICU or LSU. We treated a few patients with antifungal drugs: amphotericin B, fluconazole, and voriconazole. Antifungal treatment was given based on the patient's clinical signs, symptoms, detected fungal pathogens, and judgment of the treating consultant. Additional required managements obtained from the hospital have been described elsewhere [37-39].

\subsection{Measurements}

A pretested Case Record Form (CRF) was used to gather relevant information for the study. We collected clinical data included the nature and duration of diarrhea, fever, cough, and respiratory distress; medication history, especially antibiotic for current illness before hospitalization, a history of previous hospitalization other than the present illness; clinical examination data regarding pulse, respiratory rate, axillary temperature, and oxygen saturation. Socio-demographic characteristics included age, sex, parental age with education, parent's occupation, monthly family income, and history of breastfeeding. We also measured the weight, and height of the study participants for calculation of WHO standard Z score, mid-upper arm circumference as anthropometric measurements. Laboratory test results such as lactate dehydrogenase (LDH) level >299 U/L, Beta-D-Glucan level in the serum $>80 \mathrm{pg} / \mathrm{mL}$, and optical density (OD) for Galactomannan $>0.5$ were considered as positive. Complete blood count $(\mathrm{CBC})$ was performed at different time points considering the patient's clinical condition. To maintain homogeneity, we included $\mathrm{CBC}$ reports for analysis, which were done within $72 \mathrm{~h}$ of enrollment, and hemoglobin levels $\leq 9.3 \mathrm{~g} / \mathrm{dL}$ were considered as having anemia [40].

\subsection{Definition}

We followed the WHO definition of severe acute malnutrition, pneumonia, and severe pneumonia [40,41], surviving sepsis guidelines [42] and also previously conducted study from icddr,b for sepsis, severe sepsis, and septic shock in diarrheal children $[37,43]$.

\subsubsection{Danger Signs of Severe Pneumonia}

According to the $\mathrm{WHO}$, severe pneumonia was defined if a child had hypoxemia, cyanosis, inability to breastfeed or drink, or grunting, and general danger signs including lethargy, reduced consciousness, and seizures during enrollment [40].

\subsubsection{Critically Ill}

According to the pediatric intensive care society, children requiring the support of high dependency or intensive care unit [44] are considered critically ill. 


\subsubsection{Late-Onset Hospital-Associated Infection (LOHAI)}

LOHAI is defined as infection that appears $96 \mathrm{~h}$ after hospital admission in a patient but was absent or not incubating at the time of hospital admission. LOHAI also includes an infection occurring within three days of discharge from the hospital [40].

\subsubsection{Invasive Fungal Infection (IFI)}

In December 2019, the European Organization for Research and Treatment of Cancer and the Mycoses Study Group have published a revised and updated definitions of invasive fungal disease. They categorized invasive fungal diseases (IFDs) into three groups, "proven", "probable", and "possible" IFD [45]. Considering our clinical context, we used a modified definition of IFD. Children with SAM and positive for Galactomannan (GM) antigen, Beta-D-glucan, and real-time PCR on a blood sample were considered as having IFIs.

\subsection{Laboratory Investigations}

We performed assay for LDH, real-time PCR and ELISA (Platellia ${ }^{\mathrm{TM}}$ Aspergillus Ag for the detection of galactomannan, and Fungitell kit for the detection of $(1 \rightarrow 3)-\beta$-D-glucan) and blood culture for the detection of Candida spp., Histoplasma capsulatum, Aspergillus spp., and Pneumocystis jiroveci from blood and nasopharyngeal wash; Histoplasma capsulatum and Cryptococcus spp. from urine.

\subsection{Molecular Detection of Fungal Pathogen}

A study physician collected blood and other biological specimens following the standard operating procedure (SOP) and the samples were transported to the laboratory within 30-60 min of the collection. At the laboratory, designated lab personnel extracted total nucleic acid from each specimen using QIAamp DNA mini kit (QIAGEN) and performed real-time PCR (using ABI7500 Dx fast instrument from Applied Biosystems, Foster City, CA, USA) to identify invasive fungal pathogens named, Candida spp., Aspergillus spp., Histoplasma capsulatum, Pneumocystis jirovecii, and Cryptococcus spp. using TaqMan probes [46-48]. We had used single plex TaqMan PCR with a positive and negative control in each run for the detection of fungal pathogens in all samples. We used all TaqMan PCR primer and probe from the published article and verified with beacon designer software. For identification of the fungal antigen by ELISA, we had used Fungitell and Platellia ${ }^{\mathrm{TM}}$ Aspergillus Ag kit. Fungitell is an FDA approved, highly sensitive rapid diagnostic test kit that identifies $(1 \rightarrow 3)-\beta$-D-glucan in serum within $1 \mathrm{~h}$. Fungitell is a pan fungal marker used to identify various fungal pathogens like, Candida spp., Aspergillus spp., Histoplasma capsulatum, Pneumocystis jirovecii, and Platellia ${ }^{\mathrm{TM}}$ Aspergillus Ag kit (from Bio-Rad) for the detection GM of Aspergillus species.

\subsection{Data Analysis}

Data were entered into a statistical package for the social sciences [IBM SPSS Statistics for Windows, Version 20.0. Armonk, NY, USA: IBM Corp] and Epi-Info (version 7.0, USD, Stone Mountain, GA, USA). For descriptive analysis, we had calculated frequencies, median, means, and standard deviation as appropriate to know the proportion of IFIs caused by Candida species, Aspergillus species, Histoplasma capsulatum, Cryptococcus species, and Pneumocystis jirovecii. Categorical variables compared using Pearson's Chi-square test. In contrast, the Student's t-test was used to compare the normally distributed continuous data, and Mann-Whitney $U$ tests was used to compare non-parametric data. We considered a two-sided probability of less than 0.05 statistically significant, and the odds ratio (OR) and their $95 \%$ confidence intervals (CI) were calculated to determine the strength of association. Finally, a logistic regression analysis was done to control the confounders. 


\section{Results}

Among 168 enrolled under-5-year-old children, 138 were in the study group, and 30 were in the comparison group are presented in the Figure 1. In the study group, 15 children were with IFIs. In IFIs, six children were Candida spp. positive by PCR from the blood sample. The proportion of invasive candidiasis was $4.53 \%(6 / 138)$, and within the IFIs group, 40\% (6/15) were found to be positive for Candida spp. Aspergillus spp. was positive by PCR from the blood of 11 children among the IFIs group. The proportion of invasive aspergillosis was $7.97 \%(11 / 138)$ and within the IFIs group was $73.33 \%(11 / 15)$. The proportion of invasive histoplasmosis by PCR on blood was $0.72 \%(1 / 138)$ and was $6.67 \%$ $(1 / 15)$ within the IFIs group. In the IFIs group, three children had both invasive candidiasis and aspergillosis by PCR on blood was $0.72 \%(1 / 138)$ and was $6.67 \%(1 / 15)$ within the IFIs. In the IFIs group, three children had both invasive candidiasis and aspergillosis.

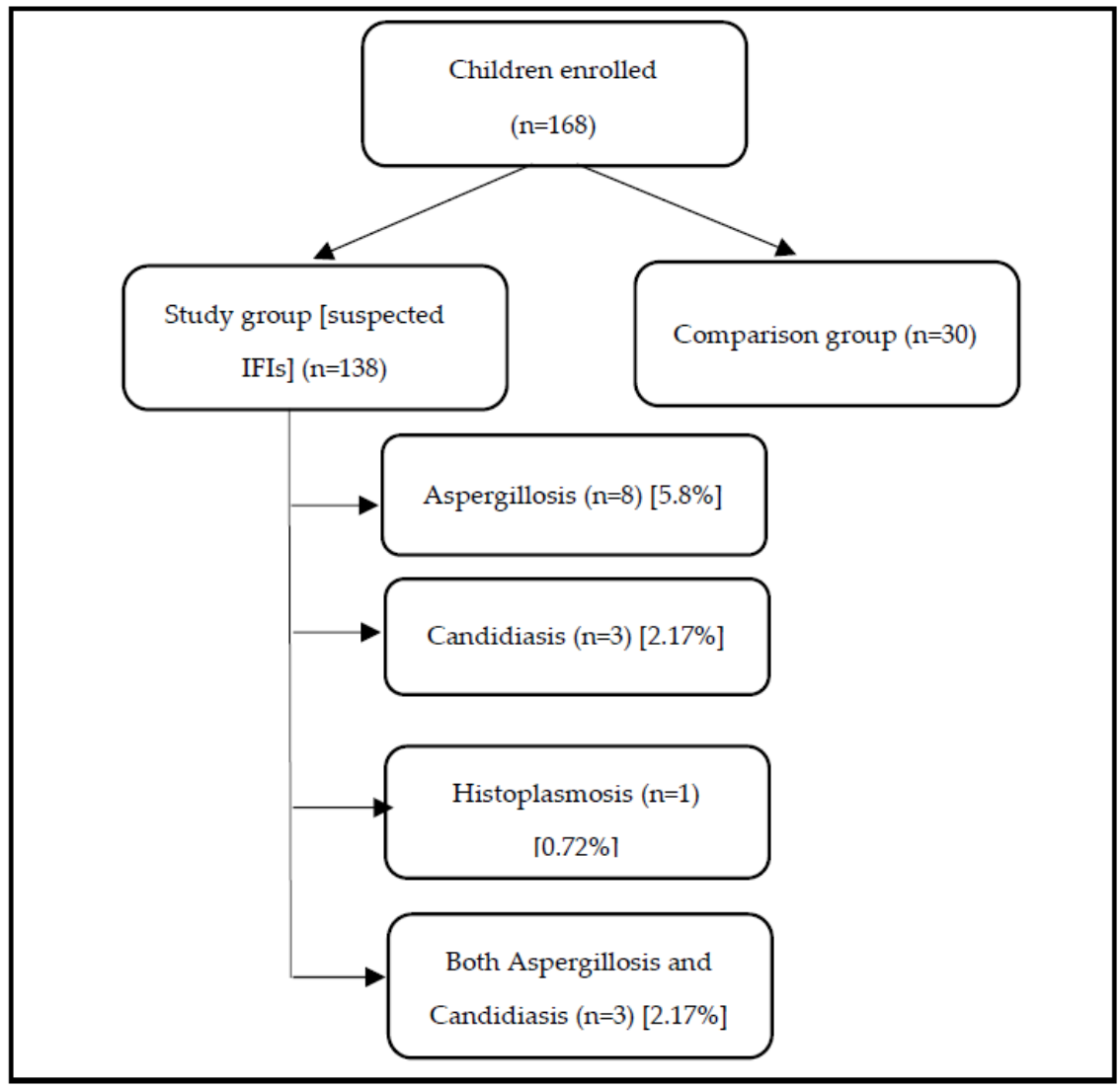

Figure 1. Proportion of children with invasive fungal infections (IFIs).

Table 1 shows that $36.2 \%(50 / 138)$ were female in the study group, whereas, in the comparison group, $20 \%(6 / 30)$ were female. The median age in months was 8 months in the study group and 9.5 months in the comparison group. The study group had less monthly family income (Table 1) and more under-fifth-grade paternal education than the comparison group (Table 1). Regarding maternal education, both groups were comparable (Table 1). A significant number of children (78.3\%) in the study group were not exclusively breastfed, had a history of previous hospital admission and fever compared to the comparison group (Table 1). The study group had lower MUAC, higher respiratory rate, and heart rate than the comparison group. The median level (interquartile range) of LDH (in U/L) and sample optical density (OD) for galactomannan (GM) was more in the study group compared to their counterpart. The study group was more likely to have higher LDH, PCR (blood), and Aspergillus positive than the comparison group. The Median (interquartile range) duration of hospitalization (in days) was more in the study group than in the comparison group. B-D-Glucan was positive in $54.3 \%(75 / 138)$ of the children in the study group. 
Table 1. Baseline characteristics of the study children.

\begin{tabular}{|c|c|c|c|c|}
\hline Variables & $\begin{array}{c}\text { Study Group } \\
n=138(\%)\end{array}$ & $\begin{array}{c}\text { Comparison Group } \\
n=30(\%)\end{array}$ & $\begin{array}{c}\text { OR (Unadjusted } \\
95 \% \mathrm{CI})\end{array}$ & $p$ Value \\
\hline Sex (Female) & $50(36.2)$ & $6(20)$ & $2.27(0.87-5.93)$ & 0.134 \\
\hline Age in months (median, IQR) & $8.0(5.0,10.0)$ & $9.5(8.0,12.5)$ & & 0.001 \\
\hline Father's age in years (mean $\pm S D$ ) & $30.78( \pm 6.9)$ & $30.1( \pm 5.5)$ & & 0.63 \\
\hline Mother's age in years mean \pm SD) & $24( \pm 5.6)$ & $23.9( \pm 4.0)$ & & 0.85 \\
\hline Monthly income in USD (median, IQR) & $179(119,239)$ & $209(179,299)$ & & 0.038 \\
\hline $\begin{array}{l}\text { No or under five grades } \\
\text { Six to ten grades } \\
\text { More than ten grades }\end{array}$ & $\begin{array}{l}63(45.7) \\
39(28.3) \\
36(26.1)\end{array}$ & $\begin{array}{c}6(20) \\
12(40) \\
12(40)\end{array}$ & & 0.034 \\
\hline $\begin{array}{l}\text { No or under five grades } \\
\text { Six to ten grades } \\
\text { More than ten grades }\end{array}$ & $\begin{array}{l}55(39.9) \\
46(33.3) \\
37(26.8)\end{array}$ & $\begin{array}{l}11(36.7) \\
8(26.7) \\
11(36.7)\end{array}$ & & 0.537 \\
\hline Day labor father & $63(45.7)$ & $10(33.3)$ & $1.68(0.73-3.85)$ & 0.302 \\
\hline Housewife mother & $127(92)$ & $28(93.3)$ & $0.82(0.17-3.93)$ & 1.000 \\
\hline Not exclusively breast feed & $108(78.3)$ & $17(56.7)$ & $2.75(1.20-6.30)$ & 0.026 \\
\hline Lives in slum & $11(8.0)$ & $5(16.7)$ & $0.43(0.14-1.35)$ & 0.259 \\
\hline H/o previous hospitalization & $67(48.6)$ & $3(10)$ & $8.49(2.46-29.30)$ & $<0.001$ \\
\hline Diarrhea & $71(51.4)$ & $30(100)$ & & $<0.001$ \\
\hline Vomiting & $20(14.5)$ & $9(30)$ & $0.39(0.16-0.99)$ & 0.076 \\
\hline Cough & $122(88.4)$ & 0 & & $<0.001$ \\
\hline Fever & $98(71.0)$ & $6(20)$ & $9.8(3.73-25.78)$ & $<0.001$ \\
\hline Poor oral intake & $50(36.2)$ & 0 & & $<0.001$ \\
\hline Respiratory distress & $78(56.5)$ & 0 & & $<0.001$ \\
\hline SAM & $72(52.2)$ & 0 & & $<0.001$ \\
\hline MUAC in cm (mean $\pm \mathrm{SD})$ & $11.34( \pm 1.76)$ & $14.66( \pm 0.78)$ & & $<0.001$ \\
\hline Respiratory rate, breaths $/$ min (mean \pm SD) & $50( \pm 12)$ & $33( \pm 5)$ & & $<0.001$ \\
\hline Heart rate, beats / min (mean $\pm \mathrm{SD})$ & $140( \pm 19)$ & $124( \pm 10)$ & & $<0.001$ \\
\hline Galactomannan (GM) positive & $62(44.9)$ & $8(26.7)$ & $2.24(0.93-5.39)$ & 0.102 \\
\hline Sample OD for GM (median, IQR) & $0.46(0.35,1.56)$ & $0.37(0.23,0.62)$ & & 0.002 \\
\hline B-D-Glucan positive & $75(54.3)$ & Not done & & \\
\hline LDH (median, IQR) & $487(364,675)$ & $299(254,351)$ & & $<0.001$ \\
\hline LDH positive & $125(90.6)$ & $15(50)$ & $9.62(3.85-24.02)$ & $<0.001$ \\
\hline PCR positive on Blood & $50(36.2)$ & $2(6.7)$ & $7.95(1.82-34.80)$ & $<0.001$ \\
\hline Candida spp. & $16(11.6)$ & 0 & & 0.079 \\
\hline Aspergillus spp. & $34(24.6)$ & $2(6.7)$ & $4.58(1.04-20.23)$ & 0.028 \\
\hline Histoplasma spp. & $7(5.1)$ & 0 & & 0.354 \\
\hline PCR positive on urine (Histoplasma only) & $8(5.8)$ & 0 & & 0.353 \\
\hline $\begin{array}{l}\text { Duration of hospitalization in days (median, } \\
\text { IQR) }\end{array}$ & $16.0(11.0,24.00)$ & $1.0(1.0,2.0)$ & & $<0.001$ \\
\hline
\end{tabular}


Table 2 shows that the clinical outcomes of children with IFIs were sick, and many of them $(13 / 15[87 \%])$ required ICU care and $(7 / 15$ [47\%]) died. Two patients $(2 / 15[13 \%])$ were referred, and both of them died (also Figure S1, supplementary file).

Table 2. Characteristics and outcomes of the children having invasive fungal infections during hospitalization.

\begin{tabular}{|c|c|c|c|c|c|c|c|c|c|c|}
\hline \multirow{2}{*}{ DOA } & \multirow{2}{*}{$\begin{array}{l}\text { Age in } \\
\text { Months }\end{array}$} & \multirow{2}{*}{ Sex } & \multirow[t]{2}{*}{$\begin{array}{l}\text { Hypoxemia } \\
\text { at } \\
\text { Enrolment }\end{array}$} & \multirow[t]{2}{*}{$\begin{array}{l}\text { Needed } \\
\text { ICU } \\
\text { Care }\end{array}$} & \multicolumn{2}{|c|}{$\begin{array}{l}\text { Underlying Clinical } \\
\text { Condition }\end{array}$} & \multicolumn{3}{|c|}{ PCR on the Blood Sample } & \multirow[t]{2}{*}{ Outcome } \\
\hline & & & & & Pneumonia & $\begin{array}{c}\text { Sepsis/Severe } \\
\text { Sepsis/Septic } \\
\text { Shock }\end{array}$ & $\begin{array}{l}\text { Candida } \\
(n=6)\end{array}$ & $\begin{array}{l}\text { Aspergillus } \\
(n=11)\end{array}$ & $\begin{array}{l}\text { Histoplasma } \\
\quad(n=1)\end{array}$ & \\
\hline 05.03.2018 & 7 & Female & No & yes & Yes & Yes & Positive & Positive & Negative & Dead \\
\hline 06.04 .2018 & 11 & Female & No & yes & Yes & & Positive & Negative & Negative & Survived \\
\hline 02.05 .2018 & 8 & Male & No & no & Yes & & Positive & Positive & Negative & Survived \\
\hline 11.05 .2018 & 6 & Female & No & yes & & Yes & Negative & Negative & Positive & Survived \\
\hline 29.06.2018 & 12 & Female & No & yes & Yes & Yes & Negative & Positive & Negative & Dead \\
\hline 08.08.2018 & 2 & Female & No & yes & Yes & & Positive & Positive & Negative & LAMA \\
\hline 16.08 .2018 & 30 & Male & Yes & yes & Yes & Yes & Negative & Positive & Negative & Referred \\
\hline 11.09 .2018 & 4 & Female & Yes & yes & Yes & Yes & Positive & Negative & Negative & Dead \\
\hline 02.10 .2018 & 3 & Male & No & yes & Yes & Yes & Negative & Positive & Negative & Dead \\
\hline 14.11.2018 & 11 & Male & Yes & yes & Yes & Yes & Negative & Positive & Negative & Referred \\
\hline 03.01.2019 & 4 & Female & Yes & yes & Yes & Yes & Negative & Positive & Negative & Dead \\
\hline 25.01.2019 & 10 & Female & Yes & yes & Yes & & Positive & Negative & Negative & Survived \\
\hline 21.02.2019 & 47 & Female & Yes & yes & Yes & Yes & Negative & Positive & Negative & Dead \\
\hline 01.02.2019 & 8 & Male & No & no & Yes & & Negative & Positive & Negative & Survived \\
\hline 22.03.2019 & 3 & Female & Yes & yes & Yes & & Negative & Positive & Negative & Dead \\
\hline
\end{tabular}

Abbreviation: LAMA- Left against medical advice, DOA- Date of Admission.

Table 3 shows the comparative characteristics of children with and without IFIs within the study group. Children with IFIs more often had female sex than those without IFIs. The median (inter-quartile range) age (in months) was comparable between the study groups. Parent's age, education, occupation, breastfeeding status of the children, antibiotic use history, and co-morbidity were also comparable between the study groups. Children with the IFIs compared to those without IFIs more frequently received inotrope during their hospital stay. Their death rate was significantly higher than those without IFIs. Danger sign of severe pneumonia was more in children with IFIs compared to those without IFIs.

Table 3. Characteristics and outcome of children with and without invasive fungal infections.

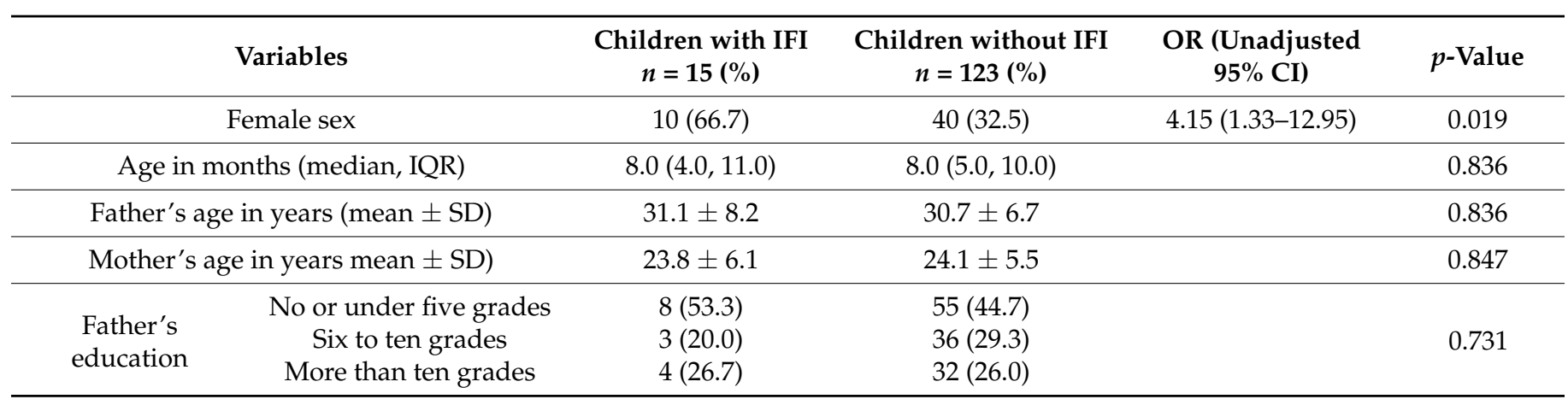


Table 3. Cont.

\begin{tabular}{|c|c|c|c|c|}
\hline Variables & $\begin{array}{c}\text { Children with } \\
\text { IFI } \\
n=15(\%)\end{array}$ & $\begin{array}{l}\text { Children without } \\
\text { IFI } \\
n=123(\%)\end{array}$ & $\begin{array}{l}\text { OR (Unadjusted } \\
\quad 95 \% \mathrm{CI})\end{array}$ & $p$-Value \\
\hline \multirow{3}{*}{$\begin{array}{l}\text { Mother's } \\
\text { education }\end{array}$} & $9(60.0)$ & $46(37.4)$ & & \multirow{3}{*}{0.215} \\
\hline & $4(26.7)$ & $42(34.1)$ & & \\
\hline & $2(13.3)$ & $35(28.5)$ & & \\
\hline Day labor Father & $7(46.7)$ & $56(45.5)$ & $1.04(0.36-3.06)$ & 0.848 \\
\hline Housewife Mother & $12(80.0)$ & $115(93.5)$ & $0.28(0.06-1.19)$ & 0.100 \\
\hline Monthly income in USD (median, IQR) & $143(119,179)$ & $179(119,239)$ & & 0.297 \\
\hline Not Exclusively Breast feed & $13(86.7)$ & $95(77.2)$ & $1.92(0.41-9.00)$ & 0.522 \\
\hline $\begin{array}{l}\text { Duration of breast feeding in months (median, } \\
\qquad \mathrm{IQR})\end{array}$ & $4.0(1.0,8.0)$ & $6.0(2.5,9.0)$ & & 0.197 \\
\hline Antibiotic use before hospital admission & $12(80.0)$ & $88(75.2)$ & $1.32(0.35-4.99)$ & 1.000 \\
\hline Developed thrush after hospital admission & $4(26.7)$ & $34(27.6)$ & $0.95(0.28-3.19)$ & 1.000 \\
\hline $\mathrm{H} / \mathrm{o}$ previous hospitalization & $6(40.0)$ & $61(49.6)$ & $0.68(0.23-2.01)$ & 0.668 \\
\hline Present co-morbidity & $2(13.3)$ & $14(11.4)$ & $1.19(0.24-5.86)$ & 0.685 \\
\hline Diarrhea & $7(46.7)$ & $64(52.0)$ & $0.81(0.28-2.36)$ & 0.905 \\
\hline Cough & $11(73.3)$ & $111(90.2)$ & $0.29(0.08-1.08)$ & 0.074 \\
\hline Fever & $8(53.3)$ & $90(73.2)$ & $0.42(0.14-1.25)$ & 0.194 \\
\hline Respiratory distress & $8(53.3)$ & $70(56.9)$ & $0.86(0.29-2.54)$ & 0.990 \\
\hline Poor oral intake & $7(46.7)$ & $43(35.0)$ & $1.63(0.55-4.79)$ & 0.544 \\
\hline Radial pulse in minute (mean \pm SD) & $136.5 \pm 18.0$ & $140.5 \pm 19.5$ & & 0.450 \\
\hline Respiratory rate in minute (mean $\pm \mathrm{SD}$ ) & $48.0 \pm 10.8$ & $50.2 \pm 12.1$ & & 0.505 \\
\hline Developed septic shock (received inotrope) & $4(26.7)$ & $6(4.9)$ & $7.09(1.24-34.75)$ & 0.013 \\
\hline Lower chest wall in drawing & $9(60)$ & $71(57.7)$ & $1.09(0.37-3.27)$ & 0.913 \\
\hline Danger sign of severe pneumonia & $8(53.3)$ & $27(22.0)$ & $4.06(1.16-14.31)$ & 0.022 \\
\hline Crackles & $10(66.7)$ & $91(74)$ & $0.70(0.22-2.21)$ & 0.767 \\
\hline Absolute neutrophil count (median, IQR) & $\begin{array}{c}6469.8(2694.9 \\
17,796.4) \\
\text { Missing } 7\end{array}$ & $\begin{array}{c}7279.1(4580.9 \\
10,289.9) \\
\text { Missing } 49\end{array}$ & & 0.710 \\
\hline Absolute lymphocyte counts (median, IQR) & $\begin{array}{c}4838.5(3427.0 \\
5902.5) \\
\text { Missing } 7\end{array}$ & $\begin{array}{c}5217.5(3827.7 \\
7334.7) \\
\text { Missing } 49 \\
\end{array}$ & & 0.710 \\
\hline $\mathrm{Hb}$ level in gm/dl (mean $\pm \mathrm{SD})$ & $\begin{array}{l}9.6 \pm 1.5 \\
\text { Missing } 6\end{array}$ & $\begin{array}{l}10.7 \pm 1.7 \\
\text { Missing } 47\end{array}$ & & 0.086 \\
\hline LDH level in (U/L) (median, IQR) & $516.0(436,1009)$ & $477.4(361.9,662.1)$ & & 0.274 \\
\hline Anemia (missing value of CBC 53) & $4(44.4)$ & $17(22.4)$ & $2.78(0.67-11.50)$ & 0.215 \\
\hline Histoplasma positive in urine by PCR & $1(6.7)$ & $7(5.7)$ & $1.18(0.13-10.34)$ & 1.000 \\
\hline LDH positive in blood & $13(86.7)$ & $112(91.1)$ & $0.64(0.13-3.20)$ & 0.634 \\
\hline $\begin{array}{l}\text { Duration of hospitalization in days (median, } \\
\text { IQR) }\end{array}$ & $10.0(9.0,17.0)$ & $17.0(12.0,24.0)$ & & 0.128 \\
\hline Got both first and second line antibiotics & $8(53.3)$ & $43(35.0)$ & $2.12(0.72-6.26)$ & 0.256 \\
\hline Death & $7(46.7)$ & $11(8.9)$ & $8.90(2.71-29.24)$ & $<0.001$ \\
\hline
\end{tabular}


From the Table 4, logistic regression analysis found that children with invasive fungal infections were independently associated with female sex after adjusting for potential confounder.

Table 4. Logistic regression analysis to find out an independent risk factor for invasive fungal infection among study group children.

\begin{tabular}{ccc}
\hline Variables & Adjusted OR with 95\% CI & $p$-Value \\
\hline Age & $1.03(0.97,1.09)$ & 0.306 \\
\hline Female sex & $3.48(1.05,11.55)$ & 0.042 \\
\hline Septic shock & $4.77(0.98,23.22)$ & 0.053 \\
\hline Danger sign of severe pneumonia & $2.34(0.68,8.02)$ & 0.175 \\
\hline
\end{tabular}

\section{Discussion}

Globally, immunocompromised children are more susceptible to develop IFIs [2]. According to the best of our knowledge, this was the first study in Bangladesh that evaluated the spectrum, frequency, associated factors, and outcome of IFIs among hospitalized ill children admitted in the critical care ward. The identification of around $11 \%$ probable IFIs among our study children is the most important observation. $4.53 \%, 7.97 \%$, and $0.72 \%$ of the children with IFIs had invasive candidiasis, aspergillosis, and histoplasmosis, respectively. Our objective was to identify fungal pathogen (Candida species, Pneumocystis jirovecii, Aspergillus species, Cryptococcus species, and Histoplasma Capsulatum), and the detection of specific species was beyond our scope. Candida spp. were associated with suppressed cell-mediated immune response, and it was the most prevalent fungal pathogen in malnourished children [49]. In developing countries like Bangladesh, invasive aspergillosis is not rare. A study from Bangladesh conducted with the aim of identifying the histopathology and etiology of childhood pneumonia found Pneumocystis carinii (PC) and Aspergillus in $4 \%$ and $3 \%$ autopsy patients, respectively. This opportunistic infection is primarily due to malnutrition and weakened host defenses throughout persistent serious illnesses [50]. Disseminated histoplasmosis could be found in children with no underlying disease other than malnutrition [51]. In our study, we did not find any children who were positive for Pneumocystis jirovecii and Cryptococcus spp. positive. Perhaps it might be due to the low prevalence of HIV in the general population in Bangladesh [52]. A study from the HIV unit of Dhaka hospital of icddr,b showed that $24 \mathrm{HIV}$-infected children were admitted over three years. Among them, 16.7\% children had Pneumocystis jirovecii pneumonia (PCP) [53]. Cryptococcosis and histoplasmosis are not frequent in Bangladesh. Bangladesh is still a low prevalent country for HIV. The first reported case of disseminated Histoplasmosis in Bangladesh was in 1982 [54]. A systematic review on Histoplasmosis from Bangladesh found 26 patients over 55 years from 1962 to 2017. All were male patients aged 8-75 years, and four had HIV/AIDS. Disseminated histoplasmosis was present in 22 patients, and four patients had localized oropharyngeal disease [55]. Among under-5-year-olds there was a case report of disseminated histoplasmosis in a 3-and-a-half-year-old boy from Bangladesh [56]. Our study also found a deficient proportion of invasive Histoplasmosis in under-5-year-old children. Shahrin et al., found six presumptive cryptococcal meningitis cases among HIV-infected adults over three years [57]. Based on this data, it was estimated that the rate of cryptococcal meningitis was $0.01(15 / 100,000)$ in each year in Bangladesh among HIV infected patients [29]. From Bangladesh, we do not find patients with cryptococcal meningitis in non-HIV patients except one case report of post-renal transplant cryptococcal meningitis [26]. In our study, we did not find any children positive with cryptococcal infection.

The European Organization for Research and Treatment of Cancer and the Mycoses Study Group Education and Research Consortium (EORTC/MSGERC) published a consensus definition of invasive fungal diseases (IFDs) in December 2019. According to the 
classification, IFD is divided into three groups, "proven", "probable", and "possible". Regarding a patient's immune status, any patient can be categorized as proven IFD if fungus is detected by microscopy or culture of the sterile material or blood culture or tissue nucleic acid diagnosis and DNA sequencing. However, probable and possible IFD are categorized only for immunocompromised patients except for endemic mycosis. There must be three-factor to be diagnosed as a probable IFD; namely host factors, clinical features, and mycological evidence. In this revised and updated definition of 2019, EORTC considered Platellia ${ }^{\mathrm{TM}}$ Aspergillus, Fungitell, and PCR as the tests for diagnosing probable IFD [45]. However, the cutoff values for these mycological tests are different from the ones that we used in our study. Since we had completed our study before this definition was published. Possible IFD defined as having host factors and clinical features without mycological evidence. Under such circumstance, we made a consensus definition of probable IFIs for our study patients. Those with severe acute malnutrition as a host factor, plus sepsis or pneumonia or both as a clinical feature, plus positive real-time PCR on blood, and Platellia $^{\mathrm{TM}}$ Aspergillus, and Fungitell as a mycological evidence were considered to be a probable IFD or invasive fungal infection.

The mortality rate was significantly higher in children with IFIs compared to those without IFIs. Children with IFIs had severe malnutrition whereas many of the children without IFIs did not have severe malnutrition due to purposeful categorization of probable IFIs. Malnutrition is one of the important causes of secondary immunodeficiency where innate and acquired immune systems might be impaired, resulting in increased susceptibility to gastrointestinal and respiratory infections $[58,59]$ and often leading to deaths [60]. Moreover, children with IFIs more often presented with danger signs of severe pneumonia and experienced septic shock than those without IFIs. Previous studies in Bangladesh found that the case-fatality rate was significantly higher in children experiencing severe pneumonia [38] or septic shock [37] compared to those who did not have these entities. Studies outside Bangladesh also revealed that children who presented with septic shock at the time of candidemia had a higher death rate $(71.4 \%$ vs. $12.5 \%)$ than those who presented with only fever [61]. Among non-neonatal pediatric episodes of invasive candidiasis, septic shock developed in approximately $21.8 \%$ cases, and attributable mortality risk was in $17.5 \%$ cases, and compared to treatment success $(67.9 \%$ vs. $13 \%)$, failure was more in the pediatric patient who had a septic shock at the onset of invasive candidiasis [62]. Surviving sepsis guidelines for children underscored the bacterial cause of sepsis in children [42]. However, in our day-to-day practice, sepsis due to fungal infection was found to be expected in malnourished children. Sepsis due to invasive fungal infections was observed to be mainly limited to immune-compromised children. A study conducted in East Africa, among malnourished hospitalized children, found that about $45 \%$ of children had diarrhea, $12 \%$ had candidiasis, and 55\% died due to sepsis, and the findings of this study are consistent with our study findings [63]. In our study, some of the reports were available after the death of a child. A few children received antifungal drugs also. However, as this was an observational study and standard care at icddr,b does not include antifungal empirically, we were unable to conclude the role of antifungal therapies in the IFI affected children.

The observation of the independent association of females with invasive fungal infection is really interesting. In countries like Bangladesh, gender bias starts from birth to throughout life. In childhood, gender bias was observed during family food allocation, education, and healthcare-seeking behavior. Female children were more likely to be severely malnourished than male children [64]. Another study from Bangladesh reported risk factors for dehydrating diarrhea and found dehydration was more common among hospitalized females than males [65]. Probably lack of healthcare-seeking behavior for a female child made them more vulnerable. A study from India conducted in a tribal community reported that mothers sought less healthcare for female children compared to male children ( $58 \%$ vs. $83.9 \%$ ), and no treatment for illness were more evident for the females than the males (42\% vs. 16.5\%) [66]. A systematic review on healthcare behavior 
for neonates from South Asia also observed similar results and found less care-seeking behavior and higher mortality among female neonates than males [67].

Our bivariate analysis observed that the lack of exclusive breastfeeding, antibiotics use before hospitalization, danger signs of pneumonia, and anemia was higher in children with IFIs than those without IFIs. However, these variables were not found to be statistically significant in the multivariate regression analysis, probably due to our small sample size. It was well reported that breast milk protects against infections through specific and nonspecific immune factors. Human milk enhances the immature immunological system among young infants and strengthens host defense mechanisms against infective and other foreign agents [68]. Moreover, anemia also aggravates this immune disturbance, especially in malnourished children [69].

Another foremost observation from our study was that fever was less common in children with IFIs than those without IFIs. As SAM was the main component of IFIs in our study, a reduced febrile response during infection is usually associated with low serum albumin and retinol-binding protein in malnutrition. Endogenous pyrogen/interleukin-1, essential for stimulating fever, is less in the amount in malnourished children [70]. Moreover, immunosuppression and lack of standard defense mechanisms in malnourished children make it hard to get classical signs of infection such as fever, pain, and inflammation [71].

Our study had several limitations. First of all, the comparison group was small compared to the study group. However, we believe the comparison group though small, added valuable background information to this study. Secondly, we were unable to perform the ELISA by Fungitell kit (to test Beta-D-Glucan) in the comparison group during the study period. Thirdly, we did not perform an HIV test for our study children as Bangladesh is low-prevalent for HIV. In our study, we had only one child with positive fungal blood culture. The isolated fungal pathogen was Candida ciferrii, a potential skin contaminant. It is noteworthy that the patient improved with ongoing antibiotics did not require any antifungals, and was discharged from the hospital after full recovery. We followed the child up to 6 months after discharge from the hospital. The patient was alive and not found to have significant complaints during follow-up.

\section{Conclusions}

Our study data demonstrate that the prevalence of probable IFIs in Bangladesh is $10.87 \%$ and is predominated by candidiasis and aspergillosis. Children with IFIs have a higher mortality rate than those without IFIs. Female children are found to be independently associated with IFIs. Identifying simple clinical risk factors may assist the clinicians in early diagnosis and treatment of IFIs that may further aid in reducing the morbidity and mortality in such children, especially in resource-limited settings.

Supplementary Materials: The following supporting information can be downloaded at: https: / / www.mdpi.com/article/10.3390/life12010094/s1, Figure S1: Characteristics of children with invasive fungal infections.

Author Contributions: The study was conceptualized and designed by N.J.S., M.M.P., T.A., S.H., D.A., C.R.A. and M.J.C.; patient enrollment and data collection was done by N.J.S., M.S., F.A. and S.N.; analysis and interpretation of data was done by N.J.S., M.M.P., T.A., S.H., D.A., C.R.A., M.S., F.A., S.N. and M.J.C.; N.J.S. prepared the original draft of the manuscript. All the authors reviewed the draft manuscript and significantly contributed to the review process. T.A. and M.J.C. supervised the analyses and writing. The corresponding authors had full access to all the data in the study and had final responsibility for the decision to submit it for publication. All authors have read and agreed to the published version of the manuscript.

Funding: This research project was funded by the core fund of icddr,b through capacity building for clinical research initiatives. icddr,b core grant number is GR-00000. We are thankful to our core donors: The governments of Bangladesh, Canada, Sweden, and the UK, for their continuous support to icddr,b. 
Institutional Review Board Statement: The study was conducted according to the guidelines of the Declaration of Helsinki, and approved by the Institutional Review Board (IRB) of icddr,b (protocol number-PR-17069 and date of approval-17 October 2017).

Informed Consent Statement: Informed consent was obtained from the children's parents/caregiver involved in the study.

Data Availability Statement: This data set contains some personal information of the study patients (such as name, admission date, month, area of residence). Our IRB has required that the personal information of the participants is not disclosed. Thus, the policy of our center (icddr,b) is that we should not make the availability of whole data set in the manuscript, the supplemental files, or a public repository. However, data related to this manuscript are available upon request and for researchers who meet the criteria for access to confidential data may contact with Armana Ahmed (armana@icddrb.org) to the Research Administration of icddr,b (http:/ /www.icddrb.org/ (Last accessed on 2 January 2022).

Acknowledgments: We thankfully acknowledge the donors for their support to icddr,b's research efforts. icddr,b is appreciative to the Governments of Bangladesh, Sweden, Canada, and the UK for providing fundamental support. We want to express our sincere gratitude to all physicians, clinical fellows, nurses, health workers, feeding team, and research assistants for their unwavering support in patient enrolment, data collection, and patient care. We acknowledge the contribution of our laboratory personnel, who rigorously had done these newer fungal diagnostic tests. We also express our sincere appreciation to parents/caregivers for their permission to enroll their children in our study.

Conflicts of Interest: There were no conflict of interest among the authors regarding the publications of this paper. The funder of this study had no role in study design; data collection, data analysis, data interpretation; in the manuscript writing; or in the decision to publish the results.

\section{References}

1. Kaushik, A.; Kest, H. The Role of Antifungals in Pediatric Critical Care Invasive Fungal Infections. Crit. Care Res. Pract. 2018, 2018, 8469585. [CrossRef]

2. Seth, R.; Xess, I.; Jana, M. Diagnosis of invasive fungal infections in children. Indian Pediatr. 2019, 56, 229-336. [CrossRef] [PubMed]

3. Wang, S.S.; Kotecha, R.S.; Bernard, A.; Blyth, C.C.; McMullan, B.J.; Cann, M.P.; Yeoh, D.; Bartlett, A.W.; Ryan, A.L.; Moore, A.; et al. Invasive fungal infections in children with acute lymphoblastic leukaemia: Results from four Australian centres, $2003-2013$. Pediatr. Blood Cancer 2019, 66, e27915. [CrossRef] [PubMed]

4. Singhi, S.; Deep, A. Invasive candidiasis in pediatric intensive care units. Indian J. Pediatr. 2009, 76, 1033-1044. [CrossRef]

5. Pana, Z.D.; Roilides, E.; Warris, A.; Groll, A.H.; Zaoutis, T. Epidemiology of Invasive Fungal Disease in Children. J. Pediatr. Infect. Dis. Soc. 2017, 6 (Suppl. 1), S3-S11. [CrossRef]

6. $\quad$ Li, W.-R.; Deng, S.-Y.; Shu, M.; Zhu, Y.; Wen, Y.; Guo, Q.; Liao, Q.; Wan, C.M. A clinical study of invasive fungal disease in children without underlying diseases. Zhongguo Dang Dai Er Ke Za Zhi Chin. J. Contemp. Pediatr. 2016, 18, 713-717.

7. Kishimoto, K.; Kasai, M.; Kawamura, N.; Ito, Y.; Yoshida, M.; Hasegawa, D.; Kawasaki, K.; Kosaka, Y. Clinical features in proven and probable invasive fungal disease in children and adolescents at a pediatric referral center: A 5-year experience. World J. Pediatr. 2019, 15, 270-275. [CrossRef]

8. Kobayashi, R.; Kaneda, M.; Sato, T.; Ichikawa, M.; Suzuki, D.; Ariga, T. The clinical feature of invasive fungal infection in pediatric patients with hematologic and malignant diseases: A 10-year analysis at a single institution at Japan. J. Pediatr. Hematol. 2008, 30, 886-890. [CrossRef] [PubMed]

9. Zaoutis, T.E.; Argon, J.; Chu, J.; Berlin, J.A.; Walsh, T.J.; Feudtner, C. The epidemiology and attributable outcomes of candidemia in adults and children hospitalized in the United States: A propensity analysis. Clin. Infect. Dis. Off. Publ. Infect. Dis. Soc. Am. 2005, 41, 1232-1239. [CrossRef]

10. Santolaya, M.E.; Alvarado, T.; Queiroz-Telles, F.; Colombo, A.L.; Zurita, J.; Tiraboschi, I.N.; Cortes, J.; Thompson, L.; Guz-man, M.; Sifuentes, J.; et al. Active surveillance of candidemia in children from Latin America: A key requirement for improving disease outcome. Pediatr. Infect. Dis. J. 2014, 33, e40-e44. [CrossRef] [PubMed]

11. Lin, G.-L.; Chang, H.-H.; Lu, C.-Y.; Chen, C.-M.; Lu, M.-Y.; Lee, P.-I.; Jou, S.-T.; Yang, Y.-L.; Huang, L.-M.; Chang, L.-Y. Clinical characteristics and outcome of invasive fungal infections in pediatric acute myeloid leukemia patients in a medical center in Taiwan. J. Microbiol. Immunol. Infect. Wei Mian Yu Gan Ran Za Zhi 2018, 51, 251-259. [CrossRef]

12. Senet, J.-M. Candida adherence phenomena, from commensalism to pathogenicity. Int. Microbiol. 1998, 1, 117-122. [PubMed]

13. Celebi, S.; Hacimustafaoglu, M.; Ozdemir, O.; Ozkaya, G. Nosocomial candidaemia in children: Results of a 9-year study. Mycoses 2008, 51, 248-257. [CrossRef] [PubMed] 
14. Aslan, N.; Yildizdas, D.; Alabaz, D.; Horoz, O.O.; Yontem, A.; Kocabas, E. Invasive Candida Infections in a Pediatric Intensive Care Unit in Turkey: Evaluation of an 11-Year Period. Pediatr. Intensiv. Care 2019, 9, 21-26. [CrossRef]

15. Pana, Z.D.; Kotzadamis, D.; Roilides, E. Invasive Candidiasis in Pediatric Intensive Care Unit: More Challenges. Pediatr. Infect. Dis. J. 2018, 37, 1309-1311. [CrossRef] [PubMed]

16. Zaoutis, T.E.; Heydon, K.; Chu, J.H.; Walsh, T.J.; Steinbach, W.J. Epidemiology, outcomes, and costs of invasive aspergillosis in immunocompromised children in the United States, 2000. Pediatrics 2006, 117, e711-e716. [CrossRef]

17. King, J.; Pana, Z.-D.; Lehrnbecher, T.; Steinbach, W.J.; Warris, A. Recognition and Clinical Presentation of Invasive Fungal Disease in Neonates and Children. J. Pediatr. Infect. Dis. Soc. 2017, 6 (Suppl. 1), S12-S21. [CrossRef]

18. López, L.F.; Valencia, Y.; Tobón, M.; Velásquez, O.; Santa, C.D.; Cáceres, D.H.; Restrepo, Á.; Cano, L.E. Childhood histoplasmosis in Colombia: Clinical and laboratory observations of 45 patients. Med. Mycol. 2016, 54, 677-683. [CrossRef] [PubMed]

19. Rahim, M.R.; Abu Saleh, A.; Miah, R.A.; Anwar, S.; Rahman, M. Pattern of dermatophyte in Bangabandhu Sheikh Mujib Medical University. Bangladesh J. Med. Microbiol. 2012, 6, 11-14. [CrossRef]

20. Rahman, M.H.; Hadiuzzaman, M.; Jaman, M.M.K.; Bhuiyan, M.; Islam, N.; Ansari, N. Prevalence of superficial fungal infections in the rural areas of Bangladesh. Iran J. Dermatol. 2011, 14, 86-91.

21. Parvin, R.; Amin, R.; Mahbub, S.; Hasnain, M.; Khan, M.A.; Miah, T.; Gupta, R.D.; Alam, B.; Ahasan, H.N. Deep Fungal Infection-An Emerging Problem in Bangladesh. J. Med. 2010, 11, 170. [CrossRef]

22. Mahbub, M.S.; Ahasan, H.N.; Miah, M.T.; Alam, M.B.; Gupta, R.D.; Arif, K.M.; Hasnain, M. Disseminated histoplasmosis. J. Med. 2010, 11, 70-73. [CrossRef]

23. Habib, R.; Islam, R.; Rahman, A.; Bhowmik, N.; Haque, A. Rhino-Orbito-Cerebral-Mucormycosis with Osteomyelitis in a Patient with Diabetes mellitus: A Case Report and Literature Review. BIRDEM Med. J. 2012, 2, 124-128. [CrossRef]

24. Haq, J.A.; Khan, M.A.; Afroze, N.; Haq, T. Localized primary renal aspergillosis in a diabetic patient following lithotripsy-a case report. BMC Infect. Dis. 2007, 7, 58. [CrossRef]

25. Hossain, A.; Islam, Q.T.; Siddiqui, M.M.R.; Tamanna, N.; Sina, H.; Rahman, M.Y.U.; Miah, M.T. Pulmonary aspergilloma. J. Med. 2009, 10, 149. [CrossRef]

26. Islam, S.; Das, A.; Islam, N. Cryptococcosis in organ transplantation. Mymensingh Med. J. 2010, 19, 142-143.

27. Research NIoP, Training-NIPORT, Health Mo, Family Welfare, ICF. Bangladesh Demographic and Health Survey 2017-2018; NIPORT/ICF: Dhaka, Bangladesh, 2020.

28. Zaoutis, T.E.; Greves, H.M.; Lautenbach, E.; Bilker, W.B.; Coffin, S.E. Risk factors for disseminated candidiasis in children with candidemia. Pediatr. Infect. Dis. J. 2004, 23, 635-641. [CrossRef] [PubMed]

29. Gugnani, H.; Denning, D.; Rahim, R.; Sadat, A.; Belal, M.; Mahbub, M. Burden of serious fungal infections in Bangladesh. Eur. J. Clin. Microbiol. Infect. Dis. 2017, 36, 993-997. [CrossRef] [PubMed]

30. Saffioti, C.; Mesini, A.; Bandettini, R.; Castagnola, E. Diagnosis of invasive fungal disease in children: A narrative review. Expert Rev. Anti-Infect. Ther. 2019, 17, 895-909. [CrossRef]

31. Jalil, R.A.; Islam, K.S.; Barai, L.; Akhter, S. Neonatal sepsis due to non-albicans Candida species and their susceptibility to antifungal agents: First report from Bangladesh. IMC J. Med. Sci. 2021, 14, 19-26. [CrossRef]

32. Ademe, M.; Girma, F. Candida auris: From Multidrug Resistance to Pan-Resistant Strains. Infect. Drug Resist. 2020, 13, 1287-1294. [CrossRef]

33. Shahunja, K.M.; Ahmed, T.; Hossain, I.; Islam, M.; Monjory, M.B.; Bin Shahid, A.S.M.S.; Faruque, A.S.G.; Chisti, M.J. Clinical and laboratory characteristics of children under five hospitalized with diarrhea and bacteremia. PLoS ONE 2020, 15, e0243128. [CrossRef]

34. Sahni, V.; Agarwal, S.K.; Singh, N.P.; Anuradha, S.; Sikdar, S.; Wadhwa, A.; Kaur, R. Candidemia-An under-recognized nosocomial infection in Indian hospitals. J. Assoc. Physicians India 2005, 53, 607-611.

35. Xess, I.; Jain, N.; Hasan, F.; Mandal, P.; Banerjee, U. Epidemiology of candidemia in a tertiary care centre of north India: 5-year study. Infection 2007, 35, 256-259. [CrossRef] [PubMed]

36. Walsh, T.J.; Gonzalez, C.; Roilides, E.; Mueller, B.U.; Ali, N.; Lewis, L.L.; Whitcomb, T.O.; Marshall, D.J.; Pizzo, P.A. Fungemia in children infected with the human immunodeficiency virus: New epidemiologic patterns, emerging pathogens, and improved outcome with antifungal therapy. Clin. Infect. Dis. 1995, 20, 900-906. [CrossRef] [PubMed]

37. Sarmin, M.; Ahmed, T.; Bardhan, P.K.; Chisti, M.J. Specialist hospital study shows that septic shock and drowsiness predict mortality in children under five with diarrhoea. Acta Paediatr. 2014, 103, e306-e311. [CrossRef]

38. Chisti, M.J.; Salam, M.A.; Smith, J.H.; Ahmed, T.; Pietroni, M.A.C.; Shahunja, K.M.; Shahid, A.S.M.S.B.; Faruque, A.S.G.; Ashraf, H.; Bardhan, P.K.; et al. Bubble continuous positive airway pressure for children with severe pneumonia and hypoxaemia in Bangladesh: An open, randomised controlled trial. Lancet 2015, 386, 1057-1065. [CrossRef]

39. Chisti, M.J.; Salam, M.A.; Ashraf, H.; Faruque, A.S.G.; Bardhan, P.K.; Hossain, I.; Shahid, A.S.M.S.B.; Shahunja, K.M.; Das, S.K.; Imran, G.; et al. Clinical risk factors of death from pneumonia in children with severe acute malnutrition in an urban critical care ward of Bangladesh. PLoS ONE 2013, 8, e73728. [CrossRef] [PubMed]

40. World Health Organization. Pocket Book of Hospital Care for Children: Guidelines for the Management of Common Childhood Illnesses; World Health Organization: Geneva, Switzerland, 2013.

41. World Health Organization. Management of Severe Malnutrition: A Manual for Physicians and Other Senior Health Workers; World Health Organization: Geneva, Switzerland, 1999. 
42. Weiss, S.L.; Peters, M.J.; Alhazzani, W.; Agus, M.S.D.; Flori, H.R.; Inwald, D.P.; Nadel, S.; Schlapbach, L.J.; Tasker, R.C.; Argent, A.C.; et al. Surviving sepsis campaign international guidelines for the management of septic shock and sepsis-associated organ dysfunction in children. Intensive Care Med. 2020, 46, 10-67. [CrossRef]

43. Chisti, M.J.; Saha, S.; Roy, C.N.; Salam, M.A. Predictors of bacteremia in infants with diarrhea and systemic inflammatory response syndrome attending an urban diarrheal treatment center in a developing country. Pediatr. Crit. Care Med. 2010, $11,92-97$. [CrossRef]

44. Society TPIC. Standards for the Care of Critically Ill Children, 4th ed.; Version 2; Portland Place: London, UK, 2010 ; p. 21.

45. Donnelly, J.P.; Chen, S.C.; Kauffman, C.A.; Steinbach, W.J.; Baddley, J.W.; Verweij, P.E.; Clancy, C.J.; Wingard, J.R.; Lockhart, S.R.; Groll, A.H.; et al. Revision and Update of the Consensus Definitions of Invasive Fungal Disease From the European Organization for Research and Treatment of Cancer and the Mycoses Study Group Education and Research Consortium. Clin. Infect. Dis. 2020, 71, 1367-1376. [CrossRef]

46. Vollmer, T.; Störmer, M.; Kleesiek, K.; Dreier, J. Evaluation of novel broad-range real-time PCR assay for rapid detection of human pathogenic fungi in various clinical specimens. J. Clin. Microbiol. 2008, 46, 1919-1926. [CrossRef]

47. Saha, D.C.; Xess, I.; Biswas, A.; Bhowmik, D.; Padma, M.V. Detection of Cryptococcus by conventional, serological and molecular methods. J. Med. Microbiol. 2009, 58, 1098-1105. [CrossRef]

48. Lorenz, M.G.; Disqué, C.; Mühl, H. Bacterial and Fungal DNA Extraction from Blood Samples: Automated Protocols. Sepsis: Diagnostic Methods and Protocols; Humana Press: New York, NY, USA, 2015; pp. 121-128.

49. Sakr, M.R.; El Aiady, A.A.; Ragab, S.H.; Gomaa, H.E.; Gamal El Din, H. Fungal and Bacterial Infection in Malnourished Children and its Relation to Severity of the Disease. J. Med. Sci. 2006, 6, 432-438. [CrossRef]

50. Tomashefski, J.F.; Butler, T.; Islam, M. Histopathology and etiology of childhood pneumonia: An autopsy study of 93 patients in Bangladesh. Pathology 1989, 21, 71-78. [CrossRef] [PubMed]

51. Tobón, A.M.; Franco, L.; Espinal, D.; Gómez, I.; Arango, M.; Trujillo, H.; Restrepo, A. Disseminated Histoplasmosis in Children: The Role of Itraconazole Therapy. Pediatr. Infect. Dis. J. 1996, 15, 1002-1008. [CrossRef] [PubMed]

52. Huq, M.N.; Khan, S.; Rahman, A.; Jahan, R.; Yasmin, S. Ending HIV/AIDS Epidemic in Bangladesh by 2030. J. AIDS Clin. Res. 2020, 11, 812. [CrossRef]

53. Shahrin, L.; Leung, D.T.; Matin, N.; Kawser, C.A.; Pervez, M.M.; Chisti, M.J. Clinical profile of hospitalized HIV-infected children in Bangladesh, a low-HIV-prevalence country. Paediatr. Int. Child Health 2013, 34, 133-137. [CrossRef]

54. Islam, N.; A Chowdhury, N. Histoplasmosis from Bangladesh: A case report. Bangladesh Med Res. Counc. Bull. 1982, 8, 21-24. [PubMed]

55. Rahim, M.A.; Ma, J.C.; Amin, M.R.; Uddin, K.N.; Chowdhury, M.J. Histoplasmosis: An emerging or neglected disease in Bangladesh? A systematic review. Oman Med. J. 2020, 35, e91. [CrossRef]

56. Khan, E.R.; Jamal, C.Y.; Karim, A.; Nigar, I.; Diba, F. A child with chronic fungal infection in Bangladesh that mimicked malignancy: Disseminated histoplasmosis. Bangladesh J. Child Health 2018, 42, 94-97. [CrossRef]

57. Shahrin, L.; Leung, D.T.; Matin, N.; Pervez, M.M.; Azim, T.; Bardhan, P.K.; Heffelfinger, J.D.; Chisti, M.J. Characteristics and predictors of death among hospitalized HIV-infected patients in a low HIV prevalence country: Bangladesh. PLoS ONE 2014, 9, e113095. [CrossRef] [PubMed]

58. Rodríguez, L.; Cervantes, E.; Ortiz, R. Malnutrition and gastrointestinal and respiratory infections in children: A public health problem. Int. J. Environ. Res. Public Health 2011, 8, 1174-1205. [CrossRef]

59. Rytter, M.J.H.; Kolte, L.; Briend, A.; Friis, H.; Christensen, V.B. The immune system in children with malnutrition-A systematic review. PLoS ONE 2014, 9, e105017. [CrossRef] [PubMed]

60. Chisti, M.J.; Salam, M.A.; Bardhan, P.K.; Faruque, A.S.G.; Shahid, A.S.M.S.B.; Shahunja, K.M.; Das, S.K.; Hossain, M.I.; Ahmed, T. Treatment Failure and Mortality amongst Children with Severe Acute Malnutrition Presenting with Cough or Respiratory Difficulty and Radiological Pneumonia. PLoS ONE 2015, 10, e0140327. [CrossRef]

61. Motta, F.A.; Dalla-Costa, L.M.; Muro, M.D.; Cardoso, M.N.; Picharski, G.L.; Jaeger, G.; Burger, M. Risk factors for candidemia mortality in hospitalized children. J. Pediatr. 2016, 93, 165-171. [CrossRef]

62. Hsu, J.-F.; Lai, M.-Y.; Lee, C.-W.; Chu, S.-M.; Wu, I.-H.; Huang, H.-R.; Lee, I.-T.; Chiang, M.-C.; Fu, R.-H.; Tsai, M.-H. Comparison of the incidence, clinical features and outcomes of invasive candidiasis in children and neonates. BMC Infect. Dis. 2018, 18, 194. [CrossRef]

63. Sunguya, B.F.P.; Koola, J.I.; Atkinson, S. Infection associated with severe malnutrition among hspitalised children in East Africa. Anzan. J. Health Res. 2009, 8, 189-192. [CrossRef]

64. Choudhury, K.K.; Hanifi, M.A.; Rasheed, S.; Bhuiya, A. Gender Inequality and Severe Malnutrition among Children in a Remote Rural Area of Bangladesh. J. Health Popul. Nutr. 2000, 18, 123-130.

65. Mahmud, I.; Das, S.; Khan, S.H.; Faruque, A.S.G.; Ahmed, T. Gender disparity in care-seeking behaviours and treatment outcomes for dehydrating diarrhoea among under-5 children admitted to a diarrhoeal disease hospital in Bangladesh: An analysis of hospital-based surveillance data. BMJ Open 2020, 10, e038730. [CrossRef]

66. Chandwani, H.; Pandor, J. Healthcare-Seeking Behaviors of Mothers regarding their Children in a Tribal Community of Gujarat, India. Electron. Physician 2015, 7, 990-997. [CrossRef] [PubMed]

67. Ismail, S.A.; McCullough, A.; Guo, S.; Sharkey, A.; Harma, S.; Rutter, P. Gender-related differences in care-seeking behaviour for newborns: A systematic review of the evidence in South Asia. BMJ Glob. Health 2019, 4, e001309. [CrossRef] 
68. Oddy, W.H. Breastfeeding protects against illness and infection in infants and children: A review of the evidence. Breastfeed. Rev. 2001, 9, 11. [PubMed]

69. Brüssow, H.; Sidoti, J.; Dirren, H.; Freire, W.B. Effect of malnutrition in Ecuadorian children on titers of serum antibodies to various microbial antigens. Clin. Diagn. Lab. Immunol. 1995, 2, 62-68. [CrossRef]

70. Kauffman, A.C.; Jones, P.G.; Kluger, M.J. Fever and malnutrition: Endogenous pyrogen/interleukin-1 in malnourished patients. Am. J. Clin. Nutr. 1986, 44, 449-452. [CrossRef] [PubMed]

71. World Health Organization, World Health Organization; Department of Child, Adolescent Health, \& UNICEF. Management of the Child with a Serious Infection or Severe Malnutrition: Guidelines for Care at the First-Referral Level in Developing Countries; World Health Organization: Geneva, Switzerland, 2000. 